\title{
Development Strategy Analysis of University Library's Pioneering Education under the Background of "Double Creation"
}

\author{
Ping Shen \\ Jiangsu Vocational Institute of Commerce, Nanjing, Jiangsu, China, 211168
}

Keywords: Double Creation Background; Creative Education; University Library; Educational Measures

\begin{abstract}
At present, the library community has undergone many changes, in which the introduction of passenger space is very representative and concept of a customer has been a lot of attention. Fellowships began to rise in colleges and universities, and university libraries can provide conditions for the development of traitors, so the university library to actively explore and boost the development of fan-off education.
\end{abstract}

\section{Introduction}

At present, "public entrepreneurship, innovation" by the whole society of widespread concern, a variety of customer content, space services are also carried out in many ways. The practice of creating a customer in the transformation of an innovative culture, students in the process of innovation and entrepreneurship will be combined with practical problems to create the design and research. "The next five to five years, comes with equipment, learning analysis and adaptive learning, enhance the reality and virtual reality, space, emotional computing, robot technology will have a significant impact on higher education." At home and abroad early Pioneer education practice is mostly for the excellent teacher's spontaneous exploration. The domestic colleges and universities are based on the specific measures and experiences of the implementation of founding students in American colleges and universities. The first batch of public demonstration schools in China, such as Tsinghua University, Shanghai Jiaotong University and Nanjing University, have set up a passenger space, paying full attention to the value of passenger education in higher education.

\section{What Is Pioneer Education}

Created originated in the West, the corresponding words in English are Maker and Hacker, focus on hands-on practice, like all kinds of creative ideas into practical applications. Foster education to promote the practice process, in the course of practice using a cooperative approach, will use all kinds of new technologies. A trainee can cultivate students' interdisciplinary application. Many foreign institutions will be an important educational teaching content to achieve interdisciplinary integration. More than 60 colleges and universities in the United States to the library as a base to open a passenger space, to carry out passenger education.

\section{The Role of Passenger Education}

The purpose of the implementation of founding students is to help the professional construction, to cultivate students' social responsibility, creative thinking and practical ability to build a cross-professional collaborative innovation of the passenger space to carry out the system of Training, results-oriented project practice and regular exchange activities, so that students become a dream to achieve home. Compared with the American colleges and universities, the founding of our college students started late and it needs to be promoted from four aspects: guest space, creative 
courses, teachers and students. At present, there are pilot schools in the field of higher education in China, and the research on the implementation of foster students in the library is still at the initial stage, which is worthy of further study.

"Education" Aspects. Educational ideas. Colleges and universities to take the initiative to adapt to the development of the times, the implementation of students' education, education starting point cannot be profit as the goal, but to cultivate students' innovation, entrepreneurial interest, this driving force will help students in the future development. Therefore, the university's foster education should combine the characteristics of young students to mobilize students' "double creation" enthusiasm as the starting point, change the original educational thoughts, teach students the basic ideas of innovation, entrepreneurship, educational thinking to achieve from teaching to learning of the change, highlighting the main characteristics of students in education, to stimulate students' "double hit" enthusiasm.

Education methods. Foster education can enhance the interpersonal communication ability and social communication ability of students, the content of education will change, and the education of students will be more prominent in the generalization of general education, so the way of education will be a corresponding change, the teaching content to eliminate the existing teaching methods to the main disciplines of the limitations, the abolition of compulsory and elective differences between the way, more emphasis on practicality of education.

"Learning" Aspects. One of the outstanding features of innovation is innovation, the original classroom teaching has been unable to adapt to the status of foster education, the education of students to be more prominent practical education. Students' learning methods are not limited to passive acceptance of classroom knowledge, and students will complete the accumulation of knowledge in exploration practice. Students will combine their own ideas, take the initiative to practice, in the course of practice to find problems and solve problems in practice to enhance innovation. Students will learn with their own hobbies, will take the initiative to obtain knowledge, learning initiative to enhance. Students will combine the learning objectives, through the practice of theoretical knowledge to the practical ability to transform, in the process of social participation to enhance the individual's ability.

\section{Advantages of Implementing Pioneer Education in University Libraries}

From the development of the current education sector, the "founding movement" is carried out in many places on a large scale. In the process of innovation, the library plays an important role, and the activities of the passenger can realize the transformation of the library function Upgrade, the main role of the library will change, in the original cultural transmission, information transmission on the basis of the provision of space, interactive communication and ideological innovation. Of the exchange, to stimulate creativity and innovation, so as to connect all the public knowledge space, innovation space. More than 60 colleges and universities in the United States to the library as a base to open a passenger space, to carry out passenger education. The library is a base of college students 'education, through the integration of theoretical knowledge and concrete practice, the project innovation-oriented curriculum learning, and the innovative practice process of students' participation. Library builds the space to become a place to attract creative activities, so that thinking, love practice students to complete innovation and entrepreneurship, and constantly develop new products. Through a wide range of innovative practice content, fundamentally lead to the quality of education in colleges and universities.

Provide Space. The space needed to create a trader is to provide an environment conducive to innovation and entrepreneurship, which is the key to the implementation of foster education in the library. Venture space is a place where people engage in practice, cooperation and exchange, product production innovation is to play a place to create creativity, creative works, new technology applications and creative resources to share the place. In the space of a passenger, a customer can carry out the exchange of ideas and creative realization. Library has a pioneer to achieve innovation, entrepreneurial conditions, the library to innovate space design, play a role in space. The library should provide space services through active practice. Some of the current domestic university 
library set up a creative space, for the activities of the founder of the foundation. The establishment of a passenger space to achieve the efficient use of library space, which is the library to adapt to the new way of education reform.

Get Knowledge. The process of creating a job requires the exchange of ideas, the formation of creative ideas, the sharing of creative processes, and these needs and library functions are consistent, the university library can achieve the collection of literature, information preservation and knowledge access and other functions. The library has a wealth of information resources, convenient network conditions, a variety of spatial combinations, can create a convenient conditions for the practice. In the vigorous development of the activities, the library ushered in the development opportunities, how to provide convenient conditions for innovative talents, how to achieve a wide range of innovative education, promote the transformation of the library development, is to determine the key to the sustainable development of the library problem.

Disciplinary Services. The library can provide disciplinary services for the development of a customer. In recent years, the development of library has made great progress, the library service has been integrated into the development of disciplines and academic research and the library can provide professional information services. The library should take the initiative to adapt to the changing requirements of the learning model, establish the service mode aiming at cultivating the innovative talents, pay attention to the interest, the way of obtaining the information and the characteristics of the behavior, and study how to provide better information service for the trader; The change of the innovation mode, the library should take the initiative to change the limitations of the original service, make good use of information resources, starting from the functional service of education, from the perspective of effective development of information resources, information services in the new education methods and educational content to play the role of library access to knowledge, to truly understand the education of entrepreneurship education trends, through innovation and development and future academic development linked to promote the development of students in the process of promoting service innovation, innovation and development.

\section{Strategies Analysis of Pioneer Education in University Libraries}

Planning Phase. Created space opened the library of new service methods and new features, the original information to provide services to change the provider of innovation space. The design and implementation process of the library space must fully consider the coordination of the structural elements of the passenger space, that is, the availability of resources, the effectiveness of resource management, the development of structural elements, and so on. Confined to the closed space, but to achieve close contact with the outside of the open space, the implementation of the function of the old and new mode update is to maintain a pioneer space continues to develop an important way.

University library for the planning of the space to take full account of the school's subject content, professional expertise, the actual conditions of the library, scientific and rational rules, according to the library's service capacity level and space to determine the actual service content. After the completion of the rules, the university library determines the content of the space to determine the location and function of the division. The size of the space to determine the combination of the nature of the activities, such as involving a large number of lectures or training on the need to have a large room to ensure that the group discussion will need to be Space is compact, in the design of space to reflect the function. In the use of space to ensure the use of efficiency, but also to ensure its use function.

Construction Phase. The construction of university library needs to know how to meet the changes of social development mode and the diversified needs of users, which is the focus of the attention of the library community. The university library is an important base to realize the innovation practice of college students. In the current educational environment, the implementation of the innovation and development of the students, for the implementation of college students practice has information, space, resources and other advantages of the first condition.In the United States colleges and universities of the practice process, often use the library as a base, this way to extend the library service function, student learning methods have also undergone a great change is 
conducive to the realization of educational innovation. Drawing on foreign advanced experience at the same time, but also to explore in line with the characteristics of Chinese university library foster education development model, according to the goal of innovation, the development of design-related training courses, including teaching content, teaching methods of innovation and evaluation system So as to enhance students' innovative practical ability.

A passenger space construction stage should pay attention to supporting facilities, can be combined with the practice of the contents of the hardware configuration. Such as various types of information processing equipment, such as computers, printers, projection, etc .; all kinds of tools, such as electric drill, machine tools, welding machines. The choice of library facilities should pay attention to practicality, taking into account the actual needs of customers, but also cannot produce a waste of funds.

Operation Phase. The practice of the customer has brought new development opportunities for the change of the service mode of the library. At the same time, the library has put forward a new standard for the original management mode and service content. University library is in the transformation of the original mode of thinking, innovative service content, for the practice of practical activities to provide the necessary role. The school can organize some lecturers or share exchange activities for the contents of the founders to facilitate students to exchange ideas and expand their horizons to help students' form innovative thinking.

Library with a guest space, we must play a role in space, to achieve the value of the use of space. The library should establish the corresponding system to ensure the effective management of the passenger space and realize the normative operation of the passenger space. The use of a passenger space to be based on the relevant articles of association, college students have time is not fixed, the content is diverse, more than the characteristics of the participants, the library to use the space to clear the conditions. The contents of the management system should also focus on the management of various types of facilities, such as various types of facilities maintenance, information equipment, software upgrades. Library improves the system through the improvement of activities to ensure the effectiveness of activities.

For the library management of space management should pay attention to play its due role. Colleges and universities can take the way of school-enterprise cooperation, so that students complete the product prototype design, students based on product market positioning, product to achieve the function of the implementation of innovative design, so that students innovative products directly to the market, the effect of guest activity. This kind of practical activities can stimulate students to participate in the enthusiasm of the one hand on the other hand students in the process of practice can enhance the ability to innovate.

\section{Conclusion}

In the course of the design and planning of the passenger space, the library should fully consider the coordination of the structural elements of the passenger space, that is, the availability of resources, the effectiveness of resource management, the renewal of the structure, activity is an open process, but the exchange of information with the outside world, the need to keep the place open, to achieve service function replacement is to maintain a successful implementation of the important content. University library is an important space for college students to practice, and there are all kinds of advantages of space, resources and talents for university students to implement foster education. Under the same time, it is necessary to explore the development model of foster students in line with the characteristics of Chinese university libraries. According to the characteristics of practice, the paper aims at the way of the education and the goal of teaching students. Teaching content is in order to enhance students' ability to innovate. To the professionalism of the service-oriented, to the professional students generally benefit from the coverage of innovative education to expand to the largest, to create a customer project as a medium to stimulate students' inner interests, the release of hidden innovation awareness, break through the boundaries of integration of multidisciplinary knowledge, through the process of innovation to create the experience, to enhance students' professional practical ability and innovation ability, and 
ultimately cultivate the needs of social development to adapt to the application of innovative talents. Therefore, the university library should change the original way to explore the "double creation" under the background of university library foster education development strategy.

\section{Acknowledgements}

Fund Project: 2017 Annual Meeting of Jiangsu Provincial Library Society, "Space Design and Maker Education Development of University Library in the Context of Double Entries" Project Number: 17YB06, Moderator: Shen Ping

\section{References}

[1] Yang Xian-min, LI Ji-hong. The Value Potential of Maker Education and Its Dispute[J]. Modern Distance Education Research, 2015 (2): 23-34

[2] He Ke-kong. On Maker Education and Creative Education [J] .Educational Research, 2016 (4): 12-24, 40

[3] Zheng Yan-lin .Analysis of the Paths to Implementing Maker Education in American Universities[J]. Open Education Research, 2015 (3): 21-29

[4] Yang Xianmin. Building a Maker Course: Connotation, Characteristics and Design Framework of "Creating a Course" [J] .Journal of Distance Education, 2016 (3): 3-14

[5] Liu Guang, Ruan Jin-qiang, Yu Wen-bo, Liu Zhi-bing. Research on Cultivating Talents in Colleges and Universities [J] Experimental Technology and Management, 2016 (4): 19-20, 31 